\title{
Prevalence Of Attrition Of Mandibular Molars In Diabetic Patients
}

Research Article

Faazila Fathima ${ }^{1}$, G. Maragathavallii ${ }^{*}$, Senthil Murugan $\mathrm{P}^{3}$

${ }^{1}$ Saveetha Dental College And Hospitals, Saveetha Institute Of Medical and Technical Sciences, Saveetha University, Chennai,600050, India.

${ }^{2}$ Professor and Head, Department of Oral Medicine, Saveetha Dental College and Hospitals, Saveetha Institute Of Medical And Technical Sciences, Saveetha University, Chennai, India.

${ }^{3}$ Associate Professor, Department of Oral Surgery, Saveetha Dental College and Hospitals, Saveetha Institute Of Medical And Technical Sciences, Saveetha University, Chennai, India.

\section{Abstract}

\begin{abstract}
Diabetes mellitus is considered a leading cause of death due to its microvascular and macrovascular complications. It is the most common non-communicable disease found in older people.Various oral manifestations are associated with diabetes. Tooth wear which is a progressive condition affects dentition throughout life. It has been accepted as a major oral health problem. Teeth wear in diabetes patients is to be evaluated to provide early and efficient treatment modalities. This study aims at evaluating the prevalence of attrition in mandibular molars in diabetic patients. This is a university setting study. 2000 patients who had diabetes were included in the study. The prevalence of attrition in mandibular molars was evaluated. The data collected was entered in SPSS and analyzed through Chi square test. It was observed that the majority $(60.7 \%)$ of the patients with diabetes had attrition in mandibular molars. Males in the age group of above 50 years showed more attrition when compared to others. Within the limitations of the study, it can be concluded that prevalence of mandibular molars attrition was significantly high in diabetic patients.
\end{abstract}

Keywords: Attrition; Diabetes; Mandibular Molar; Prevalence.

\section{Introduction}

WHO has declared diabetes to be a pandemic [1]. It's prevalence has increased dramatically over the past few decades. Diabetes mellitus is considered a leading cause of death due to its microvascular and macrovascular complications. It is the most common non-communicable disease found in older people [2]. Growth hormones and long-term steroids alter the metabolism causing diabetes. It is also associated with lifestyle disease such as obesity and sometimes with pregnancy [3, 4]. Oral manifestations in diabetes include fungal infection, bacterialinfection,oral lesions such as lichen planus, delayed wound healing, neurosensory oral disorders, dental caries and tooth loss [5, 6]. Increased manifestation of dental caries in diabetic patients are either due to increased sugar update or increased parotid salivary glucose $[7,8]$. Periodontitis is also an important complication of diabetes $[9,10]$.

Tooth wear is a progressive condition that affects dentition throughout life. It has been accepted as a major oral health problem [11]. Tooth wear affects both function and aesthetics. The most important function affected is eating due to difficulty in biting and chewing food $[12,13]$. Tooth wear includes attrition,abrasion, erosion and abfraction. Attrition is the loss of teeth occlusal surface due to the force of tooth against tooth [14].

Treatment of excessive tooth wear is complicated, expensive and time consuming. Factors related to tooth attrition include bruxism,chewing patterns etc $[15,16]$. Patients most at risk of dental wear have work and sports dehydration, caffeine addiction, gastroesophageal reflux, asthma, diabetes mellitus and hypertension $[17,18]$. Tooth wear in diabetic patients was due to increased intake of acidic food stuff and poor lifestyle habits [19]. Tooth wear can be found in all age groups [20]. However it is more prevalent and severe in adults and older people [21, 22].

Diabetes being one of the most common diseases, it is necessary to evaluate the attrition pattern in these individuals. Therefore this study was conducted to evaluate the prevalence of attrition in

*Corresponding Author:

G. Maragathavalli,

Professor and Head, Department of Oral Medicine, Saveetha Dental College and Hospitals, Saveetha Institute Of Medical And Technical Sciences, Saveetha University, Chennai, India.

Tel: +91-9445171146

E-mail: drgopalvalli@gmail.com

Received: July 21, 2020

Accepted: August 16, 2020

Published: August 26, 2020

Citation: Faazila Fathima, G. Maragathavalli, Senthil Murugan P. Prevalence Of Attrition Of Mandibular Molars In Diabetic Patients. Int J Dentistry Oral Sci. 2020;S8:02:0015:76-79. doi: http://dx.doi.org/10.19070/2377-8075-SI02-080015

Copyright: G. Maragathavalli 2020 . This is an open-access article distributed under the terms of the Creative Commons Attribution License, which permits unrestricted use, distribution and reproduction in any medium, provided the original author and source are credited. 
mandibular molars in diabetic patients.

\section{Materials and Methods}

\section{Study Setting}

This is a university setting study conducted in Saveetha dental college and hospitals. The pros of the study includes flexibility, ease of data collection and less time consumption. Cons of the study includes limited to certain demographics and limited study sample. Population selection was random. 2000 patients with diabetes were selected. Approval was obtained from the institutional study committee. The ethical approval number for the present study is SDC/SIHEC/2020/DIASDATA/0619-0320. Two examiners were involved in the study.

\section{Sampling}

It is a retrospective study. A total of 2000 case sheets were reviewed. Cross verification of data for error was done by presence of additional reviewers and by photographic evaluation. Simple random sampling was done to minimize sampling bias. It was generalized to the south Indian population. After reviewing 2000 case sheets, which were then filtered based on required data ,the final sample size was 1199 diabetic patients.

\section{Data Collection}

Data of patients who reported to Saveetha Dental College and Hospital between June 2019 to March 2020 were reviewed from the hospital management system which has records of all patient details. The data was entered in the system in a methodical manner. For the present study data of diabetic patients was filtered. Photographs and dental status of these patients were evaluated to find the prevalence of attrition in mandibular molars. The data was then entered in excel manually and imported to SPSS for analysis. Incomplete or censored data was excluded from the study.

\section{Analytics}

IBM SPSS software was used for data analysis. Independent variables included age, gender and diabetes. Dependent variables included attrition. Descriptive and inferential statistics were used. Descriptive statistics included frequency of distribution and inferential statistics included Chi square test.

\section{Results and Discussion}

The prevalence of attrition in mandibular molars was significantly high in diabetic patients. It was observed predominantly in the older age group(figure1). In the age group of 20 to 35 years, $3.25 \%$ of the diabetic patients had attrition in mandibular molars. In the age group of 36 to 50 years and above 50 years the prevalence of attrition in mandibular molars was $22.8 \%$ and $34.6 \%$ respectively. $\mathrm{P}$ value was 0.732 hence proving that association of prevalence of attrition among diabetic patients in different age groups is statistically not significant $(\mathrm{P}>0.05)$. The study population consisted of 694 males and 505 females. Mandibular molars attrition was present in $62.4 \%$ of the male diabetic patients and $58.5 \%$ in the female diabetic patients. This shows that males had more prevalence of attrition compared to females.(figure2). P value was 0.164 hence proving that association of prevalence of attrition among male and female diabetic patients is statistically not significant $(\mathrm{P}>0.05)$. It was observed that out of 1199 patients, 728 of them had attrition in mandibular molars. Only $39.2 \%$ of the study population did not have attrition in lower molars (figure3).

In a study done in Thailand including 179 diabetic patients within the age group of 35-74 years, the most prevalent type of tooth wear was attrition (99.4\%) [23]. In another study by de Carvalho Sales-Peres et al. done in patients with eating disorders, the first permanent molar was found to have significant tooth wear when compared to other teeth [24]. Study done by Venugopal [25], found the prevalence of attrition to be $93.6 \%$. In the current study, the prevalence of mandibular attrition is $61 \%$.

In accordance with the current study, previous studies also showed a similar increased prevalence of tooth wear in males [26, 27]. This can be explained by increased bite force in males than in females [28].

In a study by Bhatnagar and Gnanasundararn [29] in 2009 done in diabetic patients from Chennai population, the first molar showed to have significant tooth wear; however, this was explained by the common period of development of tooth germ of the first molar and the epithelial cells of pancreas [30-32]. Venugopal et al found in their study, the prevalence of attrition in the upper and lower molars to be more common [25].

Figure 1. Bar graph representing association between age and prevalence of attrition. $\mathrm{X}$ axis denotes age group and $\mathrm{Y}$ axis denotes the number of diabetic patients who have and do not have attrition. Presence of attrition was highest in the age group of above 50 years. [Pearson's Chi Square value $=0.624, \mathrm{df}=2, \mathrm{p}$ value $=0.732(>0.05)$; hence statistically not significant.]

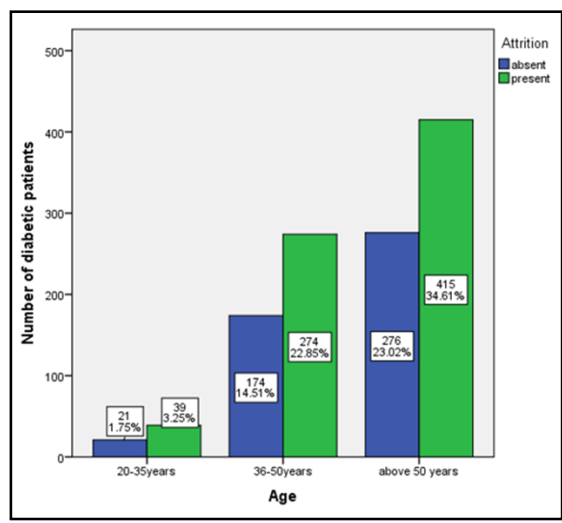


Figure 2. Bar graph representing association between gender and prevalence of attrition. $\mathrm{X}$ axis denotes gender and $\mathrm{Y}$ axis denotes the number of diabetic patients who have and do not have attrition. Attrition was present more in male diabetic patients compared to females diabetic patients. [Pearson's Chi Square value $=1.937, \mathrm{df}=1, \mathrm{p}$ value $=0.164(>0.05)$; hence statistically not significant].

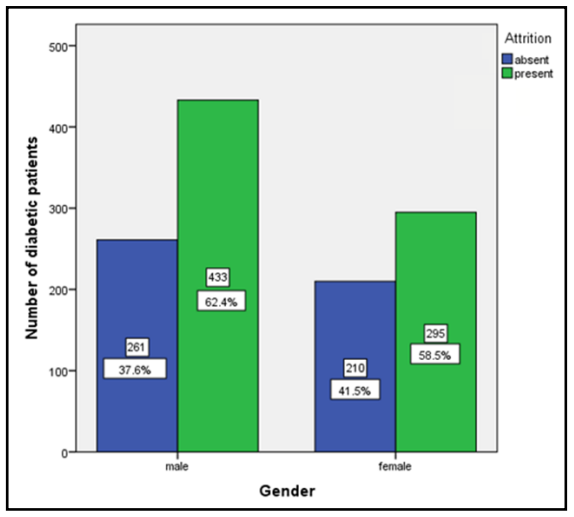

Figure 3. Bar graph representing distribution of attrition among diabetic patients. $\mathrm{X}$ axis denotes attrition and $\mathrm{Y}$ axis denotes the number of diabetic patients. This shows out of 1199 diabetic patients, $39.2 \%$ of them did not have attrition (blue) while $60.7 \%$ of the patients had attrition (green).

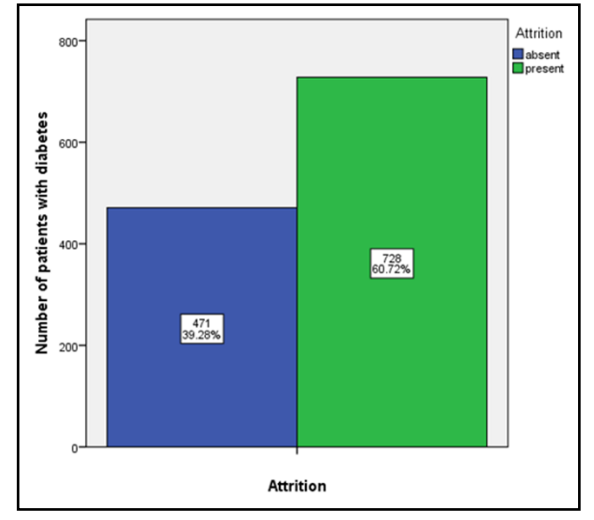

Similar to the present study,several other studies also found that the severity of tooth wear increased when age increased [22, 33].

The most common complaint caused due to tooth wear is hypersensitivity and associated poor appearance, despite the presence of advanced tooth wear,patients do not complain of pain due to secondary dentin deposition [34]. Severe loss of tooth causes the loss of vertical dimension and can cause temporomandibulardisorders [35]. This should be intervened at an early stage. The exact reason behind the increased intensity of tooth wear in the diabetic patients is unknown.It is essential to prevent the possible complications such as pulpal pain and temporomandibular joint pain at an early age.

This study could pave way for more research to be done to evaluate the teeth wear patterns in diabetic individuals so that early intervention and successful treatment outcomes can be achieved. The limitations of this study include limited to certain demographics and limited study sample.

\section{Conclusion}

Within the limitations of the study, prevalence of mandibular molar attrition was found to be significantly high in diabetic patients. Males above 50 years of age showed increased prevalence of attrition.

\section{References}

[1]. Wild S, Roglic G, Green A, Sicree R, King H. Global prevalence of diabetes: estimates for the year 2000 and projections for 2030. Diabetes Care. 2004 May;27(5):1047-53. PubmedPMID: 15111519.

[2]. Liu B, Zhang M, Chen Y, Yao Y. Tooth wear in aging people: an investigation of the prevalence and the influential factors of incisal/occlusal tooth wear in northwest China. BMC Oral Health. 2014 Jun 5;14:65. PubmedPMID: 24902953.

[3]. Taylor KW. Pathogenesis of diabetes mellitus [Internet]. Journal of Clinical Pathology. 1969; 22: 76-81.

[4]. Subashri A, Maheshwari TU. Knowledge and attitude of oral hygiene practice among dental students. Research Journal of Pharmacy and Technology. 2016 Nov $1 ; 9(11): 1840$.

[5]. Chaitanya NC, Muthukrishnan A, Krishnaprasad CMS, Sanjuprasanna G, Pillay P, Mounika B. An Insight and Update on the Analgesic Properties of Vitamin C. J Pharm Bioallied Sci. 2018 Jul-Sep;10(3):119-125. PubmedPMID: 30237682.

[6]. Dharman S, Muthukrishnan A. Oral mucous membrane pemphigoid - Two case reports with varied clinical presentation. J Indian SocPeriodontol. 2016 Nov-Dec;20(6):630-634. PubmedPMID: 29238145.

[7]. Murrah VA. Diabetes mellitus and associated oral manifestations: a review. J Oral Pathol. 1985 Apr;14(4):271-81. PubmedPMID: 3923169.

[8]. Muthukrishnan A, Bijai Kumar L. Actinic cheilosis: early intervention prevents malignant transformation. BMJ Case Rep. 2017 Mar 20;2017:bcr2016218654. PubmedPMID: 28320702.

[9]. Steele JC, Clark HJ, Hong CH, Jurge S, Muthukrishnan A, Kerr AR, et al. World Workshop on Oral Medicine VI: an international validation study of clinical competencies for advanced training in oral medicine. Oral Surg Oral Med Oral Pathol Oral Radiol. 2015 Aug;120(2):143-51.e7. PubmedPMID: 25861956.

[10]. Rohini S, Kumar VJ. Incidence of dental caries and pericoronitis associated with impacted mandibular third molar-A radiographic study. Research Journal of Pharmacy and Technology. 2017 Apr 1;10(4):1081. 
[11]. Lee A, He LH, Lyons K, Swain MV. Tooth wear and wear investigations in dentistry. J Oral Rehabil. 2012 Mar;39(3):217-25. PubmedPMID: 21923888.

[12]. Venugopal A, Uma Maheswari TN. Expression of matrix metalloproteinase-9 in oral potentially malignant disorders: A systematic review. J Oral MaxillofacPathol. 2016 Sep-Dec;20(3):474-479. PubmedPMID: 27721614.

[13]. Chaitanya NC, Muthukrishnan A, Babu DBG, Kumari CS, Lakshmi MA, Palat G, et al. Role of Vitamin E and Vitamin A in Oral Mucositis Induced by Cancer Chemo/Radiotherapy- A Meta-analysis. J ClinDiagnRes. 2017 May;11(5):ZE06-ZE09. PubmedPMID: 28658926.

[14]. O'Toole S, Pennington M, Varma S, Bartlett DW. The treatment need and associated cost of erosive tooth wear rehabilitation - a service evaluation within an NHS dental hospital. Br Dent J. 2018 Jun 22;224(12):957-961. PubmedPMID: 29880974.

[15]. Rees JS, Somi S. A guide to the clinical management of attrition. Br Dent J. 2018 Mar 9;224(5):319-323. PubmedPMID: 29495028

[16]. Maheswari TU, Venugopal A, Sureshbabu NM, Ramani P. Salivary micro RNA as a potential biomarker in oral potentially malignant disorders: A systematic review. Tzu-Chi Medical Journal. 2018 Apr;30(2):55.

[17]. Muthukrishnan A, Warnakulasuriya S. Oral health consequences of smokeless tobacco use. Indian J Med Res. 2018 Jul;148(1):35-40. PubmedPMID: 30264752 .

[18]. Muthukrishnan A, Bijai Kumar L, Ramalingam G. Medication-related osteonecrosis of the jaw: a dentist's nightmare. BMJ Case Rep. 2016 Apr 6;2016:bcr2016214626. PubmedPMID: 27053542.

[19]. Young WG. The oral medicine of tooth wear. Aust Dent J. 2001 Dec;46(4):236-50; quiz 306. PubmedPMID: 11838870.

[20]. Choudhury P, Panigrahi RG, Maragathavalli, Panigrahi A, Patra PC. Vanishing roots: first case report of idiopathic multiple cervico-apical external root resorption. J ClinDiagn Res. 2015 Mar;9(3):ZD17-9. PubmedPMID: 25954713.

[21]. Smith BG, Robb ND. The prevalence of toothwear in 1007 dental patients. J Oral Rehabil. 1996 Apr;23(4):232-9. PubmedPMID: 8730269.

[22]. Wetselaar P, Vermaire JH, Visscher CM, Lobbezoo F, Schuller AA. The Prevalence of Tooth Wear in the Dutch Adult Population. Caries Res. 2016;50(6):543-550. PubmedPMID: 27694757.

[23]. Srisilapanan P, Jindarat M, Roseman J. The Prevalence and Severity of Tooth Wear in Type 2 Diabetic Patients. Int J Dent. 2018 Dec 11;2018:3608158. PubmedPMID: 30651731.

[24]. Sales-Peres SHC, Araújo JJ, Marsicano JA, Santos JE, Bastos JRM. Preva- lence, severity and etiology of dental wear in patients with eating disorders. Eur J Dent. 2014 Jan;8(1):68-73. PubmedPMID: 24966749.

[25]. Venugopal A, Maheswari TU. Occurrence of tooth wear in controlled and uncontrolled diabetic patients-An observational study. Journal of Advanced Pharmacy Education \& Research| Jul-Sep. 2017;7(3).

[26]. Kreulen CM, Van 'tSpijker A, Rodriguez JM, Bronkhorst EM, Creugers NH, Bartlett DW. Systematic review of the prevalence of tooth wear in children and adolescents. Caries Res. 2010;44(2):151-9. PubmedPMID: 20389070.

[27]. Milosevic A, Young PJ, Lennon MA. The prevalence of tooth wear in 14-year-old school children in Liverpool. Community Dent Health. 1994 Jun;11(2):83-6. PubmedPMID: 8044716.

[28]. Cunha-Cruz J, Pashova H, Packard JD, Zhou L, Hilton TJ; for Northwest PRECEDENT. Tooth wear: prevalence and associated factors in general practice patients. Community Dent Oral Epidemiol. 2010 Jun;38(3):22834. PubmedPMID: 20370807.

[29]. Bhatnagar D, Gnanasundararn N. " Tooth marker" to diagnose diabetes mellitus. Journal of Indian Academy of Oral Medicine and Radiology. 2009 Oct 1;21(4):164.

[30]. Patil SR, Maragathavalli G, Araki K, Al-Zoubi IA, Sghaireen MG, Gudipaneni RK, et al. Three-rooted mandibular first molars in a Saudi Arabian population: A CBCT study. Pesquisabrasileiraemodontopediatria e clinicaintegrada. 2018 Aug 27;18(1):4133.

[31]. Misra SR, Shankar YU, Rastogi V, Maragathavalli G. Metastatic hepatocellular carcinoma in the maxilla and mandible, an extremely rare presentation. ContempClin Dent. 2015 Mar;6(Suppl 1):S117-21. PubmedPMID: 25821363.

[32]. Subha M, Arvind M. Role of magnetic resonance imaging in evaluation of trigeminal neuralgia with its anatomical correlation. Biomedical and Pharmacology Journal. 2019 Mar 25;12(1):289-96.

[33]. Mckenna G, Burke FM. Age-related oral changes. Dent Update. 2010 Oct;37(8):519-23. PubmedPMID: 21137843.

[34]. Bernhardt O, Gesch D, Look JO, Hodges JS, Schwahn C, Mack F, et al. The influence of dynamic occlusal interferences on probing depth and attachment level: results of the Study of Health in Pomerania (SHIP). J Periodontol. 2006 Mar;77(3):506-16. PubmedPMID: 16512766.

[35]. Wazani BE, Dodd MN, Milosevic A. The signs and symptoms of tooth wear in a referred group of patients. Br Dent J. 2012 Sep;213(6):E10. PubmedPMID: 22996509. 